\title{
ACADEMIC LITERACY, A BARRIER TO LEARNING? THE VIEWS OF ENGINEERING STUDENTS
}

\author{
Magda Pinheiro', M. Lourdes Dionísio ${ }^{2}$, Rosa M. Vasconcelos ${ }^{3}$ \\ ${ }^{1}$ University of Minho (PORTUGAL) \\ ${ }^{2}$ Research Centre in Education (CIEd), University of Minho (PORTUGAL) \\ ${ }^{3}$ President of Pedagogical Council of University of Minho, University of Minho (PORTUGAL)
}

\begin{abstract}
It is consensual, that academic literacy, which is being currently defined both as the mastery of written language in higher education (HE) and the specific reading and writing practices within fields and disciplines, involving a variety of communicative practices, and textual genres, constitutes a strong barrier to students learning and achievement. In fact, what and how one reads and writes to learn and communicate knowledge in HE contexts have particular features, which require students to adapt to new ways of understanding and organizing knowledge and to switch their writing styles and texts acquired at secondary education to others proper of such new settings. To learn and to be successful in academic context students have to deploy a repertoire of practices and genres different from those they bring to the University.

Several models have been adopted to help students to adapt their practices to those of the university and to "fix" problems that are frequently identified. In spite of the approach, all agree that it is crucial to start by understanding students perceptions of the academic literacies features, and of the kind of barriers that those particular features pose them when they have to write and to interpret, for instance, a scientific article, or a technical report.
\end{abstract}

Within this same perspective, this article discusses data from a broader study whose main goals were: 1) to understand the role of reading and writing in the teaching and learning processes of HE students; 2) to contribute to characterize academic literacies in a particular context. The achievement of these objectives has gone through, from the perceptions of a group of 30 students (1) the identification of the degree of awareness of the features of academic literacy, particularly in what concerns the texts that they have to read and write; (2) the identification of the specific barriers that textual genres comprehension and production puts to HE students; (3) the characterization of how personal (vernacular) reading and writing practices are factors of academic achievement.

The research has been conducted with students of an Integrated Master of Textile Engineering, using a questionnaire of 35 questions (5 open and 30 in Likert type scales), organized around three major themes that correspond to the above presented goals. Until now the responses were treated with descriptive statistics, through measures of central tendency such as means, medians and modes.

As preliminary analysis, it is possible to ascertain that students are aware of the specialized nature of academic reading and writing tasks as well as of the genres that circulate for learning in HE context. Students are also able to identify the linguistic and macro structural textual features that put them problems and constitute barriers to their learning.

The data obtained so far corroborate other studies, including those that conclude about the privilege given to writing over reading in $\mathrm{HE}$, and about the barriers that particular texts writing (mainly reports and scientific articles) pose to students.

Particularly relevant for the design of interventions that aim to help students overcome the barriers is the fact that the texts that students identify as giving them more difficulties are those that are more distant from the classroom: This means that students are supposed to master the reading and writing of texts that they do not encounter frequently in the classroom pedagogical process.

Keywords: Academic literacy, higher education, barriers, reading and writing practices, textual features.

\section{INTRODUCTION}

Within the perspective that sees literacy as a set of flexible cultural practices, defined and redefined by social institutions and public interests, where power relations and identities play a definitive role, 
academic literacies represent ways of knowing in different disciplines. In this case, "the disciplines are seen as a social set of ways of thinking, speaking and acting, a bakhtinian sphere of activity" [1]. Academic literacy defined then both as the mastery of written language in higher education (HE) and the specific reading and writing practices within fields and disciplines [2] involves a variety of communicative practices, and textual genres. According to this framework, a university course must be understood as a social and cultural context where texts have determinant roles. Textual genres are identified by their several structural and rhetorical characteristics. But they also share what one may call hidden features [3] [4]. Due to the centrality of discourse socialization and participation of people in teaching and learning practices, these hidden features are inferred during the processes of meaning making for specific disciplinary and academic purposes [5]. These textual features together with the features of the learning processes constitute a strong barrier to students learning and achievement. In fact, what and how one reads and writes to learn and communicate knowledge in HE contexts requires students to adapt to new ways of understanding and organizing knowledge and to switch their writing styles and texts acquired at secondary education to others proper of such new settings, as the University one. In other words, to learn and to be successful in academic contexts students have to deploy a repertoire of practices and genres different from those they bring to the University.

Several models have been adopted to help students to adapt their practices to those of the university and to "fix" problems that are frequently identified. Each of these models is associated with different understandings of what is literacy and of the ways students learn adapt to each literacy context [3] [4].

In spite of the model used, all agree that before any 'intervention' it is crucial to start by understanding students perceptions of the academic literacies features, and of the kind of barriers that those particular features may pose them when they have to write and to interpret, for instance, a scientific article, or a technical report.

\section{ACADEMIC LITERACIES: INTERVENTION MODELS}

Context par excellence of reading and writing practices, higher education is one of the privileged places for the study of the status, functions and uses of texts, particularly those that students access in the process of acquisition and production of knowledge. At the same time, the recognition that such texts are disciplinary specialized and situated, that is, that the various discursive communities have their own rules and conventions to produce knowledge and that the texts vary linguistically depending on their purpose and context of production [6] [7], extends to the field of tertiary education, the notion of literacy, in this case "academic".

In this context, we have been witnessing the multiplication of programs, measures and even courses to prepare students to master the texts and practices necessary to their academic success [3] [4] [5]. Underlying such measures we often find the "alleged inadequacy of knowledge and reading and writing skills of college students" [8] and "frequent complaint among academics that students entering the university are ill-prepared for teaching that will be exposed" [9]. In such situations, these same authors say that the "academic literacy is constituted inside deficit talks and remediation". According to the different conceptualizations of the reading and writing practices, and of the way they are learned by university students the programs, measures and courses can be categorized around three different, although not always exclusive models: a study skills model, an academic socialization model, and an academic literacies model [10] [3] [4]. For the study skills approach reading and writing are an individual and cognitive skill, and the barriers that students face reside on the surface features of the text. The academic socialization approach defends that students need to be acculturated into disciplines discourses and genres, in order to acquire the discipline specific ways of talking, writing, thinking, and using literacy. This approach takes for granted that the knowledge of the rules of a particular academic discourse allows its reproduction without difficulties. The practices that can be labeled as academic literacies focus on meaning making, and on identity, power, and authority; they also highlight the institutional nature of what counts as legitimate knowledge in any particular academic context [4]. Within this model, acquiring academically adequate uses of literacy are situated and dynamic, therefore more complex and nuanced.

Research shows that the approaches that are more frequent in the development of instructional practices have been the skills and academic socialization models [11] which are are based on what B. Street conceptualized as the "autonomous" model of literacy [12] in which literacy is considered as universal and unchanging set of technical skills, states or internal cognitive events. In this model, which opposes the "ideological" one, the measures, as described by Henderson and Hirst [9] "tend to focus on strategies to help students adapt their practices to the university", without considering, on the 
one hand, hidden "dimensions" of the writing process and particularly the criteria used by those who have the power to assess the writing" [5].

In spite of the approach, all agree that, before any initiative, it is crucial to start by understanding students perceptions of the academic literacies features, and of the kind of barriers that those particular features pose them when they have to write and to interpret, for instance, a scientific article, or a technical report.

This issue of the barriers that academic literacy can put to students is still particularly relevant when we know that in Portugal, in the last four decades, the number of students in higher education has increased very substantially due to the expansion of new HE institutions [13]. This growth corresponds to the entry of students with diverse socio-cultural backgrounds, carrying with them knowledge, experiences, interests and motivations sometimes deeply contradictory [14]. In such circumstances, access to knowledge by the part of the students is doubly hindered: they have to focus not only on new and highly specialized academic content, but also at the same time to make sense with the explicit and implicit (hidden) linguistic, structural and rethorical features of the texts they have to read and produce.

The Portuguese university context has been sensitive to this issue and it is now frequent the adoption of learning modalities, such as project led education [15] as well as the development of research that aim at coping with the difficulties that students face when they arrive at the University [16].

\section{THE EMPIRICAL RESEARCH}

Aiming at understanding 1) the role of reading and writing in the teaching and learning processes of HE students; and 2) to contribute to characterize academic literacies in a particular context, as first steps to intervene, a wider research is being developed with a group of students of a Course of Textile Engineering of one University located in the North of Portugal. Part of the specific objectives that will be handled in this presentation regard (1) the identification of the degree of awareness of the features of academic literacy, particularly in what concerns the texts that students have to read and write; (2) the identification of the specific barriers that textual genres comprehension and production puts to HE students; (3) the characterization of how personal (vernacular) reading and writing practices are factors of academic achievement. It is also pursued the aim of understanding to which point perceptions of academic literacy by the part of the students are a factor of academic performance.

\subsection{Methodology}

The research involved 30 students of the 1st year of an Integrated Master in Textile Engineering of the University of Minho, Portugal, a University with a long tradition in research and intervention on conditions for teaching and learning [17].

To survey the students a questionnaire was used, although we are aware of the limitations of such procedure [18]. Indeed, due to the fact that respondents follow the representations they build about the situation and of their own goals, it is important to ascertain that the answers only can be interpreted if related with the social conditions where they have been produced.

This questionnaire was composed of 35 questions (5 open and 30 in Likert type scales), organized around three major themes that correspond to the above presented goals: (1) degree of awareness of the features of academic literacy; (2) barriers that textual genres comprehension and production puts to students; (3) personal (vernacular) reading and writing practices as factors of academic achievement.

Data collected in the survey were processed using the SPSS statistical software, version 20 , and the responses were treated with descriptive statistics, through measures of central tendency such as means, medians and modes.

\section{ACADEMIC LITERACIES AS BARRIERS TO LEARNING: THE VIEWS OF THE STUDENTS}

In a first moment, regarding the perceptions students have about the specificities of this particular literacy, namely in what concerns reading, data show that students agree, althought not expressively, that the texts they have to read for the university course are different from texts whose reading was requested in secondary school $(37.9 \%) .48,3 \%$ state that the texts are very different from those that 
they use to read outside the university. $65.5 \%$ say that the difference varies and the variation depends on the Course Units.

When they are asked to freely declare what kind of texts they have to read for the course, students identify specific texts of their academic subject contents $(40,9 \%)$ and supporting documents of the classes, such as PPTs $(27,3 \%)$. The same kind of document is referred when they are asked about the texts that teachers recommend more frequently for reading $(50 \%)$.

In what regards writing, students seem to be also aware that what they have to write as Course tasks is different from what they had to write previously for secondary classes $(41,4 \%)$, and very different from those they have to write for their personal purposes $(52,2 \%)$. Reports are the textual genre that students say that teachers ask them to write more frequently $(68,8 \%)$.

In spite of this apparent awareness, almost half of the students $(48,3 \%)$ do not recognize that technical language is fundamental when producing texts for the Course.

Comparing to reading, a slightly smaller percentage of students $(62,1 \%)$ admit that the texts they have to write vary by Course Unit, which points to the perception of the diversity and speciality of the texts of the different disciplines.

However, when students have to self-assess their comprehension, they do not admit that their difficulties vary according the texts they have to read $(48,3 \%$ do not agree nor disagree). May be because of this, only $37,9 \%$ admit that they need to read texts closer to those of the classes. But, in spite of this, $66,7 \%$ assume that books/texts with technical/scientific terminology are the most difficult to read.

If we consider that the documents that place more or less difficulties to students can be identifiers of the academic sphere, it becomes clear that reports, scientific articles, technical books/texts and dissertations oppose less difficult newspaper texts, summaries and literature.

In what regards the perception of the specificity of the texts that they have to write, almost half of the students $(41,4 \%)$ do not agree nor disagree that they need to write texts closer to the ones of the classes, although they assume that they try that the texts that they write have similarities with those that they encounter in the classes $(51,7 \%)$.

As for reading, technical texts are also those that $44,4 \%$ of the students identifies as an example of a difficult text to write.

In what regards the barriers that students encounter when reading and writing for academic purposes, it is worth to note that $38 \%$ declare not have any difficulties; the remaining answers allow to conclude that the features that put more comprehension difficulties are associated with textual macrostructure, namely the identification of the main ideas, and the relationship between the different parts of the text. In what respects textual production, once again specific terminology and the organization of the ideas in the text are the features that put more difficulties.

Relating personal reading and writing practices with academic performance, the third goal of the survey, a great number of students $(73,3 \%)$ have the sense that "sometimes" the reading of certain texts, such as dissertations and scientific articles may constitute an obstacle to their learning. However, only $53,6 \%$ of the students admit that the way they read interfere with their academic performance. Accordingly, although in a slightly higher percentage, $64,3 \%$ of the students do not recognize that they are assessed by how they read.

A little bit different is the case of writing. In fact, $64 \%$ of the students assume that "sometimes" the way they write in texts and other assignments determines the results they get $(64 \%)$, and even that their success depends on the way they write $(37,9 \%)$.

However, when asked about what they think it is more important for their teachers, knowledge or the way the form of their writing, almost half of the students $(44,8 \%)$ believes that for their teachers knowledge is always more important; $64 \%$ of the students point that only some times they are assessed by the way they write; accordingly, $82,8 \%$ agrees that when teachers assess their tests and other assignments, knowledge is what counts for them.

\section{FINAL REMARKS}

Given the ambition of understanding the role of reading and writing in the teaching and learning of Higher Education students and to contribute to the characterization of academic literacies, in what 
they may constitute barriers to learning, we analyzed the perceptions of a group of 30 students from the $1^{\text {st }}$ year of a Master Course in Textile Engineering.

At the production level, students report that higher education texts are different from secondary school and their daily ones, the difficulties to read or produce them depending on the type of texts to be read or written. They also believe that texts are specific not only of the "global" academic context but of each Curricular Unit.

Reports and technical texts are without doubt the textual genres that appear as the typical genres of their academic sphere. Trying to make an introspection, students argue that they need to write texts closer to those that they encounter in classes, and that they try that. This specificity extends to reading, being a cause of difficulties, in particular when thesis, dissertations, technical books/texts, and scientific articles are concerned, or conceptual mediators, because they serve to acquire, to build or expand knowledge and metaknowlegde [19].

Oddly, students point that the texts that teachers more recommend for reading and the texts they read more are what one may classify as regulators of the learning process because they support students to use the conceptual knowledge focused in the course, to produce (as authors) knowledge [19].

As for the specific barriers to understand and produce texts in academic context, students identify the textual organization of ideas, the drafting and the use of specific language as the main obstacles. In terms of reading, some students do not mention having difficulties, while others indicate the identification of the main ideas of the text, the relationship between the different parts of the text and the relationship with what they know before reading. In sum, barriers are at the level of elaborative and macro processes. These difficulties are coherent with what makes academic texts different: their linguistic and rethorical features.

In what regards the hidden features, those that students have to infer, such as ambiguities, authorreader relationships, contribution to knowledge, stance, voice, signalling, among others, do not seem to be very present in these students' academic lives. Accordingly, data allowed to conclude that the more the texts are distant from the classes, more difficulties students encounter when reading or writing them.

Finally, students believe that reading and writing academic texts are crucial for their learning and therefore they are aware that the way they read and write may have impact in their academic performance.

In spite of this, students believe that they are not assessed by their reading and writing cognitive processes. Consequently, for these students, academic consequences of the way one reads is just a matter of their personal sphere.

At the level of writing, the inquired students also assume that the way they write determines their final marks. But a little bit paradoxically, they consider that their teachers value more, or almost exclusively, knowledge than the form to present it. This will explain that only a small part of the students think that only on occasion the form of their writing is assessed.

The data obtained so far corroborate other studies, including those who conclude that in academic contexts writing is privileged over reading and that the barriers to learning mainly regard reading and writing of reports ans scientific papers, etc. One can also conclude that the texts identified by students as barriers to their performance are the most distant from the classroom uses.

\section{ACKNOWLEDGEMENTS}

This work was partly funded by FEDER funds through the Operational Competitiveness Program (COMPETE) and by FCT with the projects UID/CTM/00264. The broader study is being developed at CIEd, Research Centre on Education, UID/CED/01661, UMinho.

\section{REFERENCES}

[1] T. Donahue, "Reframing "writing in the disciplines" and genre: cross-cultural exploration", Proceedings: Siget, Brazil, 2007

[2] T. Lillis, M. Scott, "Defining academic literacies research: issues of epistemology, ideology and strategy". Journal of Applied Linguistics, 4(1), pp. 5-32, 2007 
[3] M. R. Lea \& B. V. Street, "Student writing in higher education: An academic literacies approach". Studies in Higher Education, 23, pp. 157-172, 1998.

[4] M. R. Lea \& B. V. Street, The "Academic Literacies" Model: Theory and Applications, Theory Into Practice, 45:4, pp. 368-377, 2006, DOI: 10.1207/ s15430421tip4504_11

[5] B. V. Street, "'Hidden' features of academic paper writing", Working Papers in Educational Linguistics, Queen Mary, University of London, 2009. http://www.thinkingwriting.qmul.ac.uk/background9.htm

[6] C. Bazerman, "Atos de fala, gêneros textuais e sistemas de atividades: como os textos organizam atividades e pessoas". In A. Dionísio \& J. C. Hoffnagel (orgs.), Charles Bazerman. Gêneros textuais, Tipificação e Interação. S. Paulo: Cortez Editora, pp. 19-46, 2006.

[7] C. Bazerman, P. Prior, "Participating in emergent socio-literate worlds: genre, disciplinarity, interdisciplinarity". In J. Green \& R. Beach (Eds.), Multidisciplinary perspectives on literacy research, pp. 133-178. Urbana IL: NCTE, 2005

[8] W. E. Boyd \& M. Cullen, "A response to apparently low levels of numeracy and literacy amongst first year university environmental science students: a numeracy and literacy skills survey", International Research in Geographical and Environmental Education, Vol. 7, $n^{\circ}$ 2, pp. 106-121, 1998.

[9] R. Henderson \& E. Hirst, "Reframing academic literacy: Re-examining a short course for "disadvantaged" tertiary students", English Teaching: Practice and Critique, 6 (2), pp. 25-38, 2006.

[10] M. Lea, "Academic literacies: A pedagogy for course design". Studies in Higher Education, 29, pp. 739-756, 2004.

[11] M. L. Dionísio, A. Fischer, "Literacia(s) no Ensino Superior: Configurações em Práticas de Investigação", Ensino Superior em Mudança: Tensões e Possibilidades, UM. CIEd. Actas do Congresso Ibérico, pp. 289-299, 2010.

[12] B. V. Street, Social Literacies. Critical Approaches to Literacy in Development, Ethnography and Education, Harlow, Pearson, 1995

[13] J. C. Arroteia, "Aspectos da avaliação do Ensino Superior", Revista Portuguesa de Educação, vol. 13, n. ${ }^{\circ} 002$, pp. 111-123, 2000.

[14] L. Almeida \& R. Vasconcelos, "Ensino Superior em Portugal: décadas de profundas exigências e transformações”, Innovación Educativa, n. ${ }^{\circ 18, ~ p p . ~ 23-34, ~} 2008$.

[15] L. Amaral, R. Vasconcelos \& M. Pinheiro, The Tutor's Role in Student Learning, paper presented at the 8th International Conference of Education, Research and Innovation, Seville, Spain, pp. 5808-5812, 2015.

[16] A. Fischer, "Práticas de letramento acadêmico em um curso de Engenharia Têxtil: o caso dos relatórios e suas dimensões escondidas", SCRIPTA, v. 15, n. 28, pp. 37-58, 2011.

[17] N. Hattum-Janssen; R. M. Vasconcelos, "The role of the tutor in Project-Led Education: the development of an evaluation instrument", INTERTECH, pp. 27-31, 2008.

[18] R. Ghiglione \& B. Matalon, O Inquérito. Teoria e Prática. Oeiras: Celta Editora, 1997.

[19] A. Fischer \& M. L. Dionísio, Academic Literacies: reading and writing in a Course of Textile Engineering, UKLA's 46th Annual International Conference, The Changing Face of Literacy: Yesterday, Today and Tomorrow, Centro de Investigação em Educação (CIEd), Universidade do Minho, 2008. 